\title{
Substantially increased sensitivity of the spot-ELISA for the detection of anti-insulin antibody-secreting cells using a capture antibody and enzyme-conjugated insulin
}

\author{
Quirijn Vos ${ }^{1}$, Eric Claassen ${ }^{2}$ and Robbert Benner ${ }^{1}$ \\ 'Department of Cell Biology, Immunology and Genetics, Erasmus University, Rotterdam, The Netherlands, \\ and ${ }^{2}$ Department of Immunology, TNO, Medical Biological Laboratory, Rijswijk, The Netherlands
}

(Received 30 May 1989, revised received 17 August 1989, accepted 18 September 1989)

This paper describes an antibody capture spot-ELISA for the detection of anti-insulin antibody-secreting cells. The assay is based on the binding of secreted antibodies by immobilised isotype-specific capture antibodies and subsequent detection of insulin-specific antibodies with a conjugate of human insulin and alkaline phosphatase (HI-AP). Compared with the conventional approach, using antigen for coating and employing an enzyme-linked detecting antibody, this technique improved the detection of murine cells secreting anti-insulin antibodies of different IgG subclasses.

Key words: ELISA, spot-; Antibody-secreting cell; Anti-insulin antibody; IgG isotype

\section{Introduction}

Two types of assay can be used to enumerate antibody-secreting cells (ASC), namely haemolytic (Jerne and Nordin, 1963; Gronowicz et al., 1976)

Correspondence to: Q. Vos, Department of Cell Biology, Immunology and Genetics, Erasmus University, P.O. Box 1738, 3000 DR Rotterdam, The Netherlands.

Abbreviations: AMP, 2-amino-2-methyl-1-propanol; AP, alkaline phosphatase; ASC, antibody-secreting cell(s); 5-BCIP, 5-bromo-4-chloro-3-indolyl phosphate; BSA, bovine serum albumin; CFA, complete Freund's adjuvant; ELISA, enzymelinked immunosorbent assay; GA, glutaraldehyde; GAM, isotype-specific goat antiserum directed against mouse immunoglobulins; GAM-AP, conjugate of GAM and AP; HI, human insulin; HI-AP, conjugate of $\mathrm{HI}$ and AP; IgSC, immunoglobulin-secreting cell(s); MCA, monoclonal antibody; PBS, phosphate-buffered saline; PBT 0.1, PBS containing 0.1\% BSA and $0.1 \%$ Tween 20; PBT 1.0, PBS containing 1.0\% BSA and 0.1\% Tween 20; PLN, popliteal lymph node; PNP, p-nitrophenyl phosphate; RAM, rat MCA directed against mouse immunoglobulins. and reverse haemolytic (Eby et al., 1975) plaque assays and secondly, spot-ELISA techniques (Czerkinsky et al., 1983; Sedgwick and Holt, 1983).

Haemolytic plaque assays are limited by difficulties in coupling certain antigens to red cells (Golub et al., 1968; Pasanen and Mäkelä, 1969), instability of the products and the inability to determine the isotype of antibody contributing to direct plaque formation (Wortis et al., 1969). The sandwich spot-ELISA is more flexible and has been used for the simultaneous detection of distinct types of ASC (Czerkinsky et al., 1988a), enumeration of lymphokine-producing lymphocytes (Czerkinsky et al., 1988b; Versteegen et al., 1988) and a variety of other studies (Holt et al., 1984; Logtenberg et al., 1986; Bos et al., 1988; Zigterman et al., 1988).

In order to study the murine immune response to insulin we decided to develop a sandwich spotELISA for anti-insulin ASC, but found difficulty in detecting ASC of the different IgG subclasses. 
We adopted an antibody capture approach (Clark and Adams, 1977; Crook and Payne, 1980; Vos and Benner, 1989) using a new method for coupling proteins to alkaline phosphatase (Claassen and Adler, 1988) to resolve the problem. This spot-ELISA permitted the detection of cells secreting munine anti-insulin antibodies of the various IgG subclasses.

\section{Materials and methods}

\section{Reagents}

2-amino-2-methyl-1-propanol (AMP), alkaline phosphatase (AP), 5-bromo-4-chloro-3-indolyl phosphate (5-BCIP), bovine serum albumin (BSA), glutaraldehyde (GA), lysine $\mathrm{HCl}$ and $p$ nitrophenyl phosphate were obtained from Sigma Chemical Co., St. Louis, MO. Isotype-specific goat anti-mouse (GAM) Ig antisera and antiserum-alkaline phosphatase conjugates (GAM-AP) were obtained from Southern Biotechnology, Birmingham, AL. Human semisynthetic monocomponent insulin (HI) was obtained from Novo Biolabs, Bagsvaerd, Denmark. Complete Freund's adjuvant (CFA) was from Difco, Detroit, MI. Glycerol and Tween 20 were from Merck, Darmstadt, F.R.G. RPMI 1640 culture medium was from Gibco, Glasgow, Scotland. Monoclonal rat anti-mouse $\kappa$ light chain (RAM- $\kappa$ ) (Yelton et al., 1981) and monoclonal mouse IgG1, $\kappa$ anti-insulin p.10 (Vos and Benner, 1989) were purified by affinity chromatography and their protein content was determined by spectrophotometry at 280 $\mathrm{nm}$.

\section{Preparation of enzyme-conjugated insulin}

A conjugate of $\mathrm{HI}$ and AP was prepared according to Claassen and Adler (1988). $5 \mathrm{mg} \mathrm{AP}$ were dissolved in $2 \mathrm{ml}$ phosphate-buffered saline (PBS) and extensively dialysed against PBS. Next, GA was added to the dialysis fluid to a concentration of $0.2 \%$ and incubated overnight at $4^{\circ} \mathrm{C}$. Excess GA was removed by dialysis of the reaction mixture against $\mathrm{PBS}$ and the activated AP was transferred to a test tube containing a solution of $5 \mathrm{mg} \mathrm{HI}$ in $4 \mathrm{ml}$ PBS. After overnight incubation at $4^{\circ} \mathrm{C}, 0.25 \mathrm{ml} 0.2 \mathrm{M}$ lysine $\mathrm{HCl}$ was added, the mixture incubated for $2 \mathrm{~h}$ at room temperature, purified by dialysis against PBS, filter-sterilized, diluted $1 / 1$ with glycerol, and stored at $-20^{\circ} \mathrm{C}$.

\section{Immunization of mice}

Male BALB/c mice, 16 weeks of age, were immunized with $20 \mu \mathrm{g} \mathrm{HI}$ in $50 \mu \mathrm{l}$ of an emulsion of PBS/CFA $(1 / 1)$ in both rear footpads according to Schroer et al. (1979).

\section{Preparation of cell suspensions}

Cell suspensions from popliteal lymph nodes (PLN) were prepared as described by Benner et al. (1981). Concentrations of PLN cells and p.10 hybridoma cells (Vos and Benner, 1989) were determined with a Coulter Counter (Coulter Electronics, Luton, U.K.).

\section{Sandwich ELISA}

96 well plates (Titertek no. 77-172-05, Flow Laboratories, Zwanenburg, The Netherlands) were coated with $100 \mu \mathrm{l}$ of a $10 \mu \mathrm{g} / \mathrm{ml}$ solution of $\mathrm{HI}$ in PBS by incubating for $1 \mathrm{~h}$ at $37^{\circ} \mathrm{C}$. Next the plates were postcoated by adding $100 \mu 1$ of PBS containing 1\% BSA and 0.1\% Tween 20 (PBT 1.0) to each well and incubating for $0.5 \mathrm{~h}$ at $37^{\circ} \mathrm{C}$. After postcoating the plates were incubated with $100 \mu 1$ of different concentrations of MCA p.10 in PBT 1.0. After $1 \mathrm{~h}$ of incubation at $37^{\circ} \mathrm{C}$ and three washes with PBS containing 0.1\% BSA and $0.1 \%$ Tween 20 (PBT 0.1), $100 \mu 1$ of a $1 / 1000$ dilution of GAM-IgG1-AP in PBT 1.0 were added, after which the plates were incubated for $1 \mathrm{~h}$ at $37^{\circ} \mathrm{C}$. After five washes with PBT $0.1,100 \mu 1$ of substrate solution containing 0.2\% PNP in AMP buffer (Sedgwick and Holt, 1983) were added. After $1 \mathrm{~h}$ of incubation at $37^{\circ} \mathrm{C}$ extinctions were determined spectrophotometrically (Titertek, Multiscan, Flow Laboratories, Irvine, U.K.).

\section{Antibody capture ELISA}

96 well plates were coated with $100 \mu 1$ of a solution containing $10 \mu \mathrm{g} / \mathrm{ml}$ of GAM-IgG1 in PBS. Next the plates were treated according to the sandwich ELISA protocol with the exception of the detection of the MCA, for which $100 \mu l$ of a $1 / 100$ dilution of HI-AP in PBT 1.0 were used instead of GAM-IgG1-AP. 


\section{Sandwich spot-ELISA}

96 well plates were coated with $100 \mu 1$ of a solution of $10 \mu \mathrm{g} / \mathrm{ml}$ of $\mathrm{HI}$ in PBS by incubation for $1 \mathrm{~h}$ at $37^{\circ} \mathrm{C}$. Next the plates were postcoated by adding $100 \mu \mathrm{l}$ RPMI 1640 containing $1 \%$ BSA to each well and incubating for $0.5 \mathrm{~h}$ at $37^{\circ} \mathrm{C}$. After postcoating $100 \mu \mathrm{l}$ of cell suspensions of different concentrations in RPMI 1640 containing $1 \%$ BSA were added and the plates were incubated for $6 \mathrm{~h}$ at $37^{\circ} \mathrm{C}$ in a vibration-free, $5 \% \mathrm{CO}_{2}$ incubator. Next the plates were washed three times with PBT 0.1 and $100 \mu 1$ of a $1 / 1000$ dilution of GAM-AP in PBT 1.0 were added to each well, after which the plates were incubated overnight at room temperature. After five washes with PBT $0.1,100 \mu 1$ of substrate solution containing $0.1 \%$ 5-BCIP in AMP buffer were added. After $1 \mathrm{~h}$ of incubation at $37^{\circ} \mathrm{C}$ the supernatants were discarded and the plates were washed three times with distilled water. The spots, identifiable by the presence of insoluble enzyme reaction product, were counted using a colony viewer (Bellco Glass, Vineland, NJ).

\section{Antibody capture spot-ELISA}

96 well plates were coated with $100 \mu \mathrm{l}$ volumes of solutions containing $10 \mu \mathrm{g} / \mathrm{ml} \mathrm{GAM}$ or RAM- $\kappa$ in PBS. Next the plates were treated according to the sandwich spot-ELISA protocol except for the detection of secreted immunoglobulins. Plates coated with GAM received $100 \mu \mathrm{l}$ of a $1 / 50$ dilution of HI-AP in PBT 1.0 for the detection of anti-insulin antibody-secreting cells (ASC), whereas plates coated with RAM- $\kappa$ and incubated with $100 \mu \mathrm{l}$ of a $1 / 1000$ dilution of GAM-IgG1-AP in PBT 1.0 were used to detect IgG1 immunoglobulin secreting cells (IgSC).

\section{Results}

In order to improve a sandwich spot-ELISA for anti-insulin ASC, which used HI for coating and GAM-AP for antibody detection, a spot-ELISA employing capture antibodies was developed. To detect insulin binding, a conjugate of $\mathrm{HI}$ and $\mathrm{AP}$ was prepared according to a method (Claassen and Adler, 1988) that ensured a minimal change in the immunogenic structure of the insulin mole-

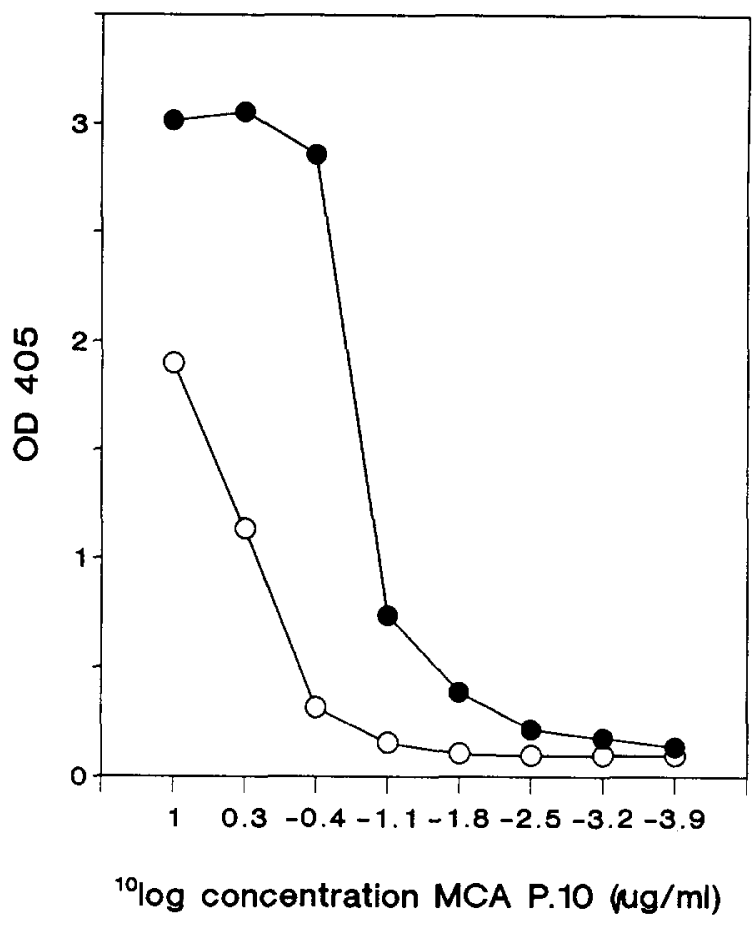

Fig. 1. Titration curves of anti-insulin MCA p.10 using the two types of ELISA described. O, plates were coated with HI and titrated with purified MCA. The detector antibody was GAMIgG1-AP. ๑, plates were coated with GAM-IgG-1 and titrated with purified MCA. HI-AP was used for detection.

cule. An ELISA was used to compare the sensitivity of the capture-coating system with the sensitivity of the antigen-coating system. Fig. 1 shows the results from this comparison for the $\operatorname{IgG} 1, \kappa$ antiinsulin MCA p.10. Both titration curves show that the capture system was approximately 25 times more sensitive than the system that employed antigen for coating. Results from the analysis of a panel of anti-insulin MCA showed improvements in sensitivity, that ranged from 10 to 100 times (data not shown).

Based on these results, the capture system was employed in an antibody capture spot-ELISA. Fig. 2 shows results from three types of spotELISA for p.10 hybridoma cells. Secretion of immunoglobulins was assayed by a system using RAM- $\kappa$ for coating, and GAM-IgG1-AP for detection. Fig. $2 A$ shows that this system detected immunoglobulin secretion in $50 \%$ of the hybridoma cells. Fig. $2 B$ shows the relative sensitivity of detection of $\mathrm{HI}$-specific ASC by the sand- 

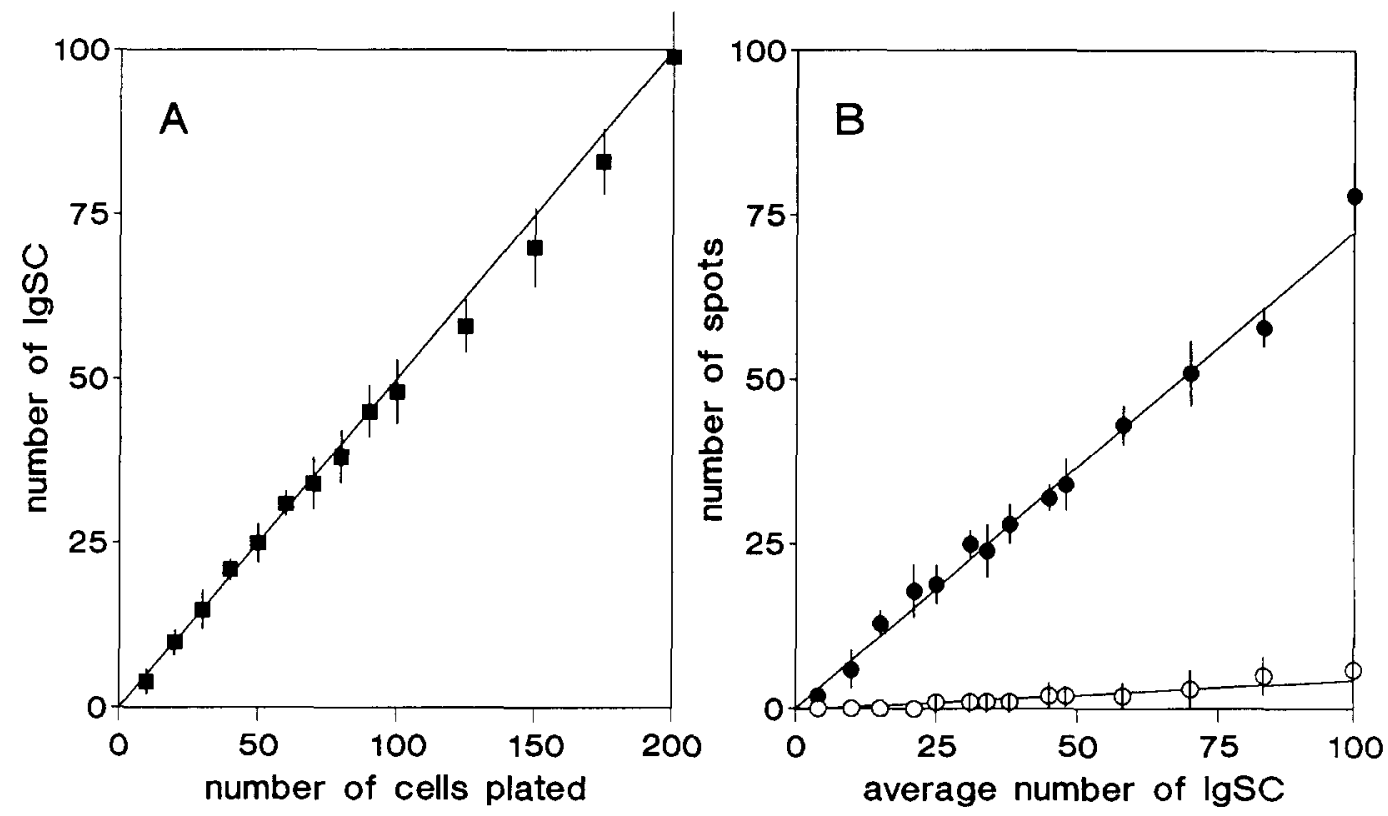

Fig. 2. Spot-ELISA of p.10 anti-insulin hybridoma cells. $A$ : detection of immunoglobulin secretion. Plates were coated with RAM- $\kappa$ and various concentrations of cells were added. The detector antibody was GAM-IgG1-AP. B: detection of anti-insulin ASC. O, plates were coated with HI and cells were added in different concentrations. The detector antibody was GAM-IgG1-AP. @, plates were coated with GAM-IgG-1 and various concentrations of cells were added. HI-AP was used for detection. Results are expressed as mean numbers $\pm \mathrm{SD}(n=8)$.

wich and antibody capture spot-ELISAs. The data show that the antibody capture spot-ELISA detected approximately $75 \%$ of the immunoglobulin (IgSC), whereas the sandwich spot-ELISA, detected only $5 \%$. Results from the analysis of a panel of anti-insulin hybridomas of IgG1 and IgG2 isotypes confirmed these percentages (data not shown).

To test the new method on a polyclonal population of anti-insulin ASC, BALB/c mice were immunized with HI in CFA in both rear footpads. Popliteal lymph node (PLN) cells were isolated on various days after immunization and assayed for anti-insulin ASC. Fig. 3 shows the kinetics of the anti-insulin ASC response of the IgM, IgG1, IgG2a and IgG2b isotypes assayed by the sandwich and the antibody capture spot-ELISA techniques. These results illustrate the improvements that the use of a coating of capture antibodies and detection of secreted antibodies with an antigen-AP conjugate may bring to the conventional spotELISA for the detection of ASC of the various IgG subclasses.

\section{Discussion}

This paper describes a spot-ELISA for anti-insulin ASC. The use of capture antibodies to bind secreted antibodies and HI-AP to detect insulin binding resulted in a spot-ELISA with an improved sensitivity for murine ASC of the various IgG subclasses. This improvement may be explained by an increase in the avidity of the plate-binding interaction, which will be greater for dimeric IgG than for pentameric IgM. Moreover the sensitivity of the conventional spot-ELISA for IgM ASC may be attributed to the size of the IgM molecule, which can be simultaneously bound by a number of enzyme-linked second antibody molecules.

The quality of the antigen-AP conjugate is crucial in the performance of the spot-ELISA based on capture antibodies. The conjugation method described mildly activates the AP using glutaraldehyde (GA), resulting in a minimal inactivation and intermolecular crosslinking of the enzyme molecule. After removing excess GA the antigen is conjugated under conditions of neutral 

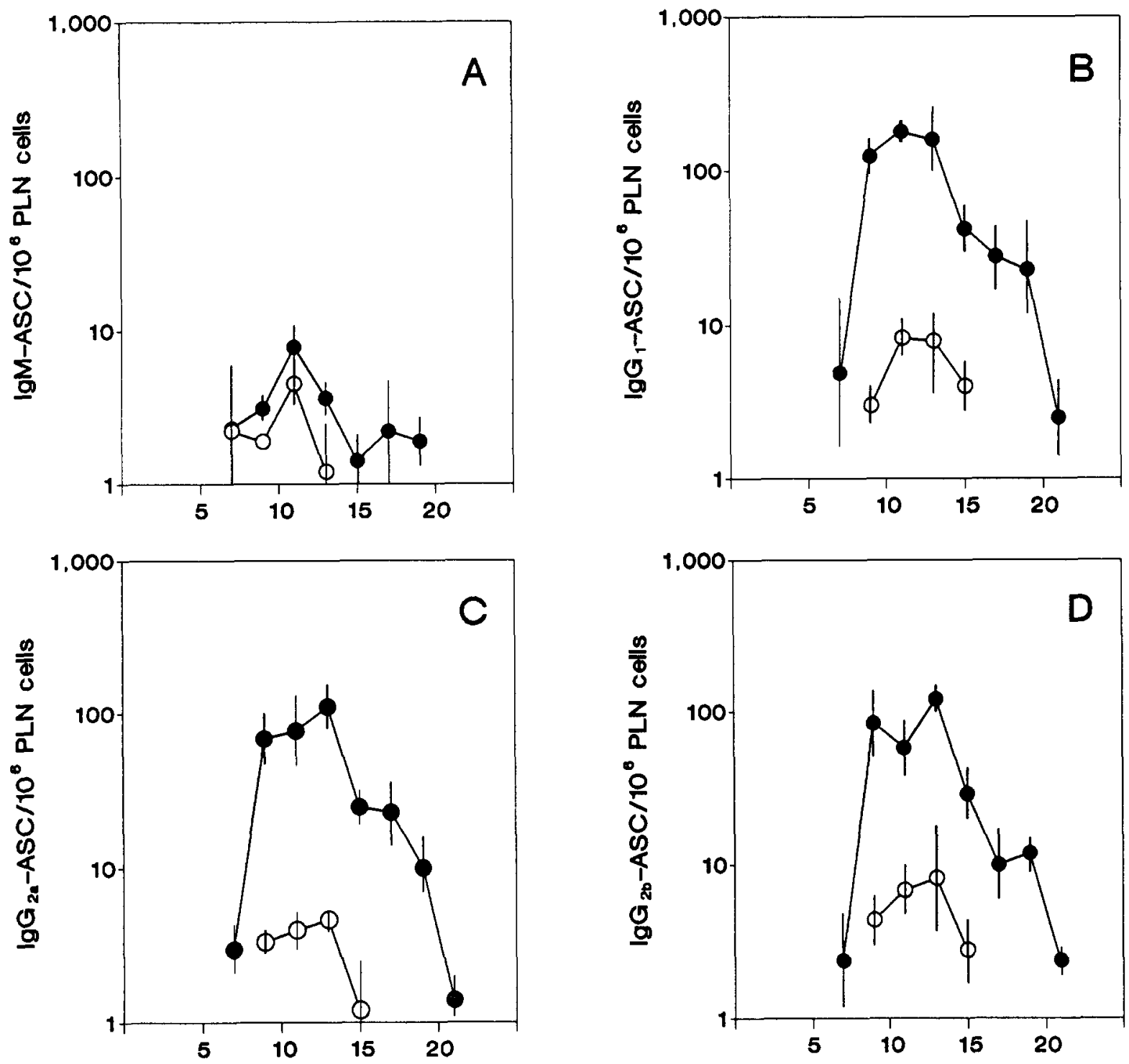

days after immunization

Fig. 3. Kinetics of the primary anti-insulin ASC response in the popliteal lymph nodes of mice immunized with HI. Detection of ASC with two types of spot-ELISA. $A$ : IgM ASC. $B$ : IgG1 ASC. $C$ : IgG2a ASC. $D$ : IgG2b ASC. $O$, plates were coated with HI and cells were added in different concentrations. The detector antibody was GAM-AP against the various isotypes. $\bullet$, plates were coated with GAM against the various isotypes and different concentrations of cells were added. HI-AP was used for detection. Results are expressed as geometric mean \pm SEM $(n=3)$. During the first 5 days of the response no anti-insulin ASC could be detected. Results lower than $1 \mathrm{ASC} / 10^{6} \mathrm{PLN}$ cells are not shown.

$\mathrm{pH}$ and low salt concentration without the presence of organic solvents. These conditions make this method applicable for a large variety of protein antigens.

The use of capture antibodies for coating al- lows this spot-ELISA to be employed for the enumeration of ASC of different antibody isotypes and potentially to different species. In order to achieve optimal binding of secreted antibodies, the capture antibody should be as pure as possi- 
ble. Purified MCA or affinity purified polyclonal antibodies are most suitable for this purpose. If a choice is to be made between different antibody preparations, an ELISA similar to the one described in Fig. 1 may be useful for performance testing.

The use of this spot-ELISA may facilitate studies of isotype-switching and other aspects of the kinetics of immune responses. Another possible application of this spot-ELISA is the simultaneous detection of cells secreting antibodies of different specificities.

\section{Acknowledgements}

The authors thank Robin Huisman for the preparation of the monoclonal antibodies to insulin, Dr. Nico Bos for his expert advice and Diana Heinsius and Geertje De Korte for skilfully typing the manuscript.

\section{References}

Benner, R., Van Oudenaren, A. and Koch, G. (1981) Induction of antibody formation in mouse bone marrow. In: I. Lefkovits and B. Pernis (Eds.), Immunological Methods, Vol. 2. Academic Press, New York, p. 247.

Bos, N.A., Meeuwsen, C.G., Wostmann, B.S., Pleasants, J.R. and Benner, R. (1988) The influence of exogenous antigenic stimulation on the specificity repertoire of background immunoglobulin-secreting cells of different isotypes. Cell. Immunol. 112, 371.

Claassen, E. and Adler, L.T. (1988) Sequential double immunocytochemical staining for in situ identification of an auto-anti-allotype immune response in allotype-suppressed rabbits. J. Histochem. Cytochem. 36, 1455.

Clark, M.F. and Adams, A.N. (1977) Characteristics of the microplate method of enzyme-linked immunosorbent assay for the detection of plant viruses. J. Gen. Virol. 34, 475.

Crook, N.E. and Payne, C.C. (1980) Comparison of three methods of ELISA for baculoviruses. J. Gen. Virol. 46, 29.

Czerkinsky, C., Nilsson, L.-Å., Nygren, H., Ouchterlony, Ö. and Tarkowski, A. (1983) A solid-phase enzyme-linked immunospot (ELISPOT) assay for enumeration of specific antibody-secreting cells. J. Immunol. Methods 65, 109.

Czerkinsky, C., Moldoveanu, Z., Mestecky, J., Nilsson, L.-Å., Ouchterlony, Ö. (1988a) A novel two colour ELISPOT assay. I. Simultaneous detection of distinct types of antibody-secreting cells. J. Immunol. Methods 115, 31.

Czerkinsky, C., Andersson, G., Ekre, H.-P., Nilsson, L.-Å., Klareskog, L. and Ouchterlony, Ö. (1988b) Reverse ELI-
SPOT assay for clonal analysis of cytokine production. I. Enumeration of gamma-interferon-secreting cells. J. Immunol. Methods 110, 29.

Eby, W.C., Chong, C.A., Dray, S. and Molinaro, G.A. (1975) Enumerating immunoglobulin-secreting cells among peripheral human lymphocytes. A hemolytic plaque assay for a B cell function. J. Immunol. 115, 1700.

Golub, E.S., Mishell, R.J., Weigle, W.O. and Dutton, R.W. (1968) A modification of the hemolytic plaque assay for use with protein antigens. J. Immunol. 100, 133.

Gronowicz, E., Coutinho, A. and Melchers, F. (1976) A plaque assay for all cells secreting Ig of a given type or class. Eur. J. Immunol. 6, 588.

Holt, P.G., Cameron, K.J., Stewart, G.A., Sedgwick, J.D. and Turner, K.J. (1984) Enumeration of human immunoglobulin-secreting cells by the ELISA-plaque method: IgE and IgG isotypes. Clin. Immunol. Immunopathol. 30, 159.

Jerne, N.K. and Nordin, A.A. (1963) Plaque formation in agar by single antibody-producing cells. Science 140, 405 .

Logtenberg, T., Kroon, A., Gmelig-Meyling, F.H.J. and Ballieux, R.E. (1986) Production of anti-thyroglobulin antibody by blood lymphocytes from patients with autoimmune thyroiditis, induced by the insolubilized autoantigen. J. Immunol. 136, 1236.

Pasanen, V.J. and Mäkelä, O. (1969) Effect of the number of haptens coupled to each erythrocyte on haemolytic plaque formation. Immunology 16, 399.

Schroer, J.A., Inman, J.K., Thomas, J.W. and Rosenthal, A.S. (1979) H-2-linked Ir gene control of antibody responses to insulin: I. Anti-insulin plaque-forming cell primary responses. J. Immunol. 123, 670.

Sedgwick, J.D. and Holt, P.G. (1983) A solid-phase immunoenzymatic technique for the enumeration of specific antibody-secreting cells. J. Immunol. Methods 57, 301.

Versteegen, J.M.T., Logtenberg, T. and Baillieux, R.E. (1988) Enumeration of IFN- $\gamma$-producing human lymphocytes by spot-ELISA. A method to detect lymphokine-producing lymphocytes at the single-cell level. J. Immunol. Methods $111,25$.

Vos, Q. and Benner, R. (1989) Analysis of anti-insulin antibodies using time-resolved fluoroimmunoassay. J. Immunol. Methods 122, 43.

Wortis, H.H., Dresser, D.W. and Andersson, H.R. (1969) Antibody production studied by means of the localized haemolysis in gel (LHG) assay. III. Mouse cells producing five different classes of antibody. Immunology 17, 93.

Yelton, D.E., Desaymard, C. and Scharff, M. (1981) Use of monoclonal anti-mouse immunoglobulin to detect mouse antibodies. Hybridoma 1, 5 .

Zigterman, G.J.W.J., Verheul, A.F.M., Ernste, E.B.H.W., Rombouts, R.F.M., De Reuver, M.J., Jansze, M., Snippe, H. and Willers, J.M.N. (1988) Measurement of the humoral immune response against Streptococcus pneumoniae type 3 capsular polysaccharide and oligosaccharide containing antigens by ELISA and ELISPOT techniques. J. Immunol. Methods 106, 101. 